\title{
Collegium Internationale Allergologicum
}

This new Association has been formed as the result of discussions between leading workers in Europe, America and elsewhere.

The aims of the Collegium are the study of scientific and clinical problems in allergy and related subjects, and the promotion of friendly co-operation and closer professional relations between all those workers who are guided solely by the humble spirit of true scientific enquiry.

The Collegium will have only a limited number of individual members - those who are actively engaged in research in the above-mentioned fields, and who have the mutual desire to exchange ideas and scientific information with the minimum of restrictive formality. To this end the Collegium will organise symposiums and arrange meetings for a limited number of participants in circumstances that will allow of the full, free and informal discussion of matters of common interest, and which it is hoped will stimulate and co-ordinate research in all branches of allergy. It is anticipated that members will be kept fully informed not only of the results of the latest work, but also of the trends of future research.

It should be noted that the Collegium will not in any way interfere or compete with any existing Allergy Society. Indeed it is hoped that the Collegium will foster and actively promote the aims of all existing Allergy Societies, and furthermore that it will exert a powerful restraining influence on all those non-scientific considerations and disruptive activities which are such disturbing features of some sections of the allergy world, and which, it is felt, must be checked before they threaten the whole structure so carefully and patiently built for us by the pioneers. The administration of the Collegium will be based upon the right of the youngest member to rank with his senior colleague, upon the equal voice of the smallest nation and of the greatest in the management of the Collegium, and upon the spirit of goodwill and mutual understanding. The sole purpose of the Collegium is the advancement of the study of allergy.

The list of Founder-Members will be announced at an early date.

David Harley, M.D., London W 1 (President). Paul Kallós, M.D., Helsingborg (Secretary). 